\title{
Impact of Early Childhood Education on Pupils' Learning in Primary Schools in Kenya
}

\author{
Jacinta, R. M. \\ Garissa Teachers College, Kenya \\ E-mail: jacintaruguru@gmail.com \\ Rotich, K. S. \\ Garissa University College, Kenya \\ E-mail: rotichkipkorir94@gmail.com
}

Received: February 9, 2015

Accepted: April 20, 2015

Published: May 25, 2015

doi:10.5296/gjes.v1i1.7686

URL: http://dx.doi.org/10.5296/gjes.v1i1.7686

\begin{abstract}
The research focused on the impact of Early Childhood Education (ECE) in the learning of pupils in primary schools in Kenya. The study employed descriptive survey design. The target population of the study was 616 teachers in the 32 public primary school in Starehe Division of Nairobi County. The sample comprised of 210 randomly selected primary school teachers. Data were gathered by use of questionnaire. Findings revealed that pupils who had gone through the ECE were able to acquire skills in basic counting, mathematics and speaking. Pupils who had not attended ECE classes had problems with grasping simple counting skills and simple language skills. They were not able to interact well with other pupils. The findings also revealed that pupils who had attended ECE classes were able to interact with the teachers better than those who had not attended ECE. Findings indicated that pupils who had attended the ECE classes had usually lower scores at the beginning in class one. Attending ECE classes enabled pupils become fluent in reading and in recognizing numbers in mathematics. The study concluded that ECE classes had prepared pupils to join primary school by enabling them learn some basic counting and speaking skills. The study recommended that parents should be sensitized on the need to take their children to the ECE centers before taking them to formal primary schools.
\end{abstract}

Keywords: Early childhood education, Learning, Impact 


\section{Introduction}

Throughout the past 200 years many countries had questioned the value of early childhood education and what role this early education plays in subsequent academic achievement and socialization in the primary grades. Against this backdrop, many parents have been on the dilemma of deciding whether or not to send their children to early childhood education (Gregory, 2004). The foregoing concern was the basis for the initiative of the convention on the rights of the child, drafted by the United Nations Commission on Human Rights (UNCHR) and adopted by the General Assembly of the UN in 1989 (United Nations Children's Fund [UNICEF], 1998). Most countries have turned to universal pre-primary education in order to give children a belter start to life (Myers, 1995; OECD, 2002; UNESCO, 2004).

There is however some general agreement among experts around the world from developing as well as developed nations that early childhood care and education programs are not only desirable but essential for many children (Sylva \& Pugh, 2005).

Gregory (2004) argues that early childhood education years are the most important for teaching a child how to love learning. In addition, children also learn how to communicate with others, how to express their feelings and how to develop their creative educational abilities. Success in pre-school establishes a foundation for a child's later academic and emotional development. Blau and Currie (2004) and Heckman (2006) argue that attending pre-primary school increases average grades, class participation, behavioral skills, socialization and self-control in primary schools. Moreover, behavioral skills are as important as cognitive skills to future success in life.

In Kenya, for many years, since the Government took over the management of ECE services through the Presidential Circular Number One of 1980, there has been a debate on the trajectories for delivering early childhood education. The objectives of Early Childhood Development Programme in Kenya include: providing education geared towards development of the child's mental and physical capabilities; It is also aimed at improving the status of the child's health; care and nutritional needs, and link him/her with health services such as immunization, health check-ups and growth monitoring and promotion. It is also aimed at enriching the child's experiences to enable him/her cope better with primary schools life (MoE, 2008).

Among the drastic changes that children encounter when moving from one environment to the next-are: changes in attitudes on the part of both teachers and parents; changes in expectations; changes in classroom arrangement, an increase in the number of subjects; and changes in the learning processes (Tiwari, 1997). The Government of Kenya is already implementing measures that seek to improve the learning of pupils undertaking early childhood education. These include establishing guidelines and standards for the management, supervision and curriculum development for ECDE; establishment of National Centers for Early Childhood Education (NACECE) and District Centers for Early Childhood Education (DICECE) for purposes of in-servicing teachers and training of trainers. It also involves mobilizing communities and parents through awareness creation, and providing community 
support grants to support marginalized/vulnerable communities in collaboration with other education partners such as NGOs (MoE, 2008).

The aim of the pre-school education or early childhood education is to provide an array of educational and social services to children. Early childhood education programs are designed to foster general well-being and enhance school readiness, so that these children might gain the full benefit of their school experiences and be more successful in life generally (Barnett 1995). As a result, the majority of children are provided care and educational experiences from adults other than parents during the years critical to brain development and learning (U.S. Census Bureau, 2003).Indeed, there is some concern that separating pre-primary age children from their mothers while they are working may have detrimental effects on child development (Clive \& Belfield, 2004).

Evidence on how early childhood education affects school readiness and subsequent educational performance is limited. Early childhood education programs promote academic skills which are important on later education of the children (Cascio, 2004). The benefits from high-quality intensive early education interventions facilitate cognitive development which in long-term increases in academic achievement of the children in later schooling (Barnett, 1995; Karoly, 1998; Currie, 2001). The bulk of evidence suggests that early childhood education during the third and fourth year of life enhances academic outcomes at school entry, but that the effects fade over the first year or two of school (Barnett, 1995; Gilliam \& Zigler, 2001). These are rated more important than specific skills such as naming letters of the alphabet or counting numbers (Entwisle \& Dauber, 1993).

According to Smith (2003) high-quality, intensive ECE programs have positive effects on cognitive development, school achievement and completion. Young children learn best through engaging in spontaneous and reciprocal interactions, meaningful activities and caring relationships. Therefore ECE should be carefully planned, be staffed by skilled and trained people and involve small groups with favourable staff-child ratios if it is to have positive effects. Participating in stimulating, warm and responsive ECE programs supports children's excitement and pleasure in learning and encourages ongoing engagement in learning activities which prepares them for future education at primary school.

Early childhood education aims at enhancing educational achievements accomplished at home and develop new age appropriate competence and also giving early access to knowledge and skills that improve performance in the first years of primary education. Duflo (2001) suggests that attending pre-primary school had a positive effect on subsequent third grade standardized Spanish and Mathematics test scores (Berlinski \& Galiani, 2006; Gregory, 2004) estimated that one year of early childhood education increased average third grade test scores by $8 \%$ of a mean or by $23 \%$ of the standard deviation of the distribution of test scores. He further found out that pre-primary school attendance positively affected student's behavioral skills such as attention, effort, class participation, and discipline.

An Early Childhood Longitudinal Study, Magnuson, Ruhm and Waldfogel (2005) found out that ECE was associated with higher reading and mathematics skills at primary school entry, but that these correlations disappeared by the end of first grade. Moreover, behavioral skills 
were noted as important as cognitive skills to future success in life (Blau \& Currie, 2004). Findings across studies (Sammons et al., 2004; Blau \& Currie, 2004) suggest that children from diverse populations benefit from educational programs prior to school entry, but in particular, high-risk children living in high poverty tend to benefit from preschool experience. ECE participation was linked to short- and long-term increases in pupil achievement as measured by school success indicators such as increased cognitive ability and academic achievement, improved social skills, lower retention and special education rates, and increased graduation rates. In addition, long-lasting effects related to other quality of life indicators included higher education attainment levels, increased economic status and decreased incidence of crime

According to Iowa School Board Foundation (2007), Pre-school attendance is associated with short and long-term, positive effects on academic performance-. The board noted that children who attended preschool tended to enter primary school with increased cognitive abilities, higher literacy abilities, and higher subject abilities. Children who had attended ECE maintained academic performance advantage over children who had not. It was also noted that children who had attended ECE have higher literacy and subject achievement scores inprimary school. They also had had better attitudes toward learning and school than peers who did not receive early childhood education prior to primary school entry (Ramey et al., 2000).

In a study by Magnuson (2004) it was revealed that early childhood education significantly raises math and reading performance at school entry - effect sizes range from 0.10 to 0.12 in the preferred models. It was also found out that early childhood education attendance decreased aggression and increased self-control -with effect sizes of 0.07-0.11. 3). It also had positive effects on academic outcomes and negative impacts on behavior, although these were smaller than for early childhood education.

Kutnick (2006) carried out a study to determine whether ECE curriculum made a difference in primary school performance in the Caribbean Island of Trinidad. The study adopted a focused sample, cross-sectional design to explore the types of preschool experience available. This was denoted by types of ECE activities which equated broadly to curriculum approaches and whether variation in preschool experience affected core curriculum performance. Findings showed that a large majority of the sampled children had attended ECE and that most of the ECE experience were traditional and teacher centred. Neither child centred nor teacher centred ECE activities affected academic performance in the core subjects during the primary school years or at the end of their primary school.

However, Vandell and Wolfe (2000) argue that it is not clear whether typical ECE programmes improve children's cognitive and academic outcomes. However, literature by Duncan and Gibson, (2000) suggests that early education may increase children's academic skills and possibly misbehavior, but is limited because most experimental studies focus on model programs serving small non-representative samples, whereas larger and more representative studies have typically not adequately addressed the selection biases that may pervade non-experimental designs. According to Cebe (2006) pupils who received cognitive 
early education in kindergarten learned better and applied more effectively a range of new academic knowledge in the two years that immediately followed the intervention than did comparable children who did not receive cognitive early education. Findings from the Carolina Abecedarian Project found that children who participated in the Abecedarian early childhood intervention maintained higher cognitive (IQ) scores through age 15 than control students who did not participate in the preschool intervention (Campbell \& Ramey, 1994). Although the advantage difference between groups of children decreased over time, long-term differences remained statistically significant.

According to Schweinhart (1993) there remains a clear advantage for children who attended pre-school compared with those who did not (the 'home' group).Children who attended pre -school have higher attainment levels than 'home' children at reception. This gap in average attainment between the pre-school and 'home' groups appears to remain consistent across time. This suggests that the experience of pre-school is particularly important in raising attainment levels in the early primary years and that 'home' children from unskilled manual backgrounds are likely to fall further behind other children. This group does not appear to catch up but suggesting that without the experience of pre-school it may be harder for poorer children to cope with the demands of the early years at school.

The ecological theory developed by Bronfenbrenner (1979) focuses on the relationship between the child and society stressing on the importance of child rearing in its social context. The ecological environment is seen as composed of four interlocking structured levels, including the most immediate settings such as home, school and work, and the interaction between these immediate settings and larger social settings. With Bronfenbrenner's ecological theory that emphasises the importance of seeing child education in its social contexts, the study examines the macro and micro levels of ECE through literature review and questionnaire.

The context of this study is the debate about the effects of Early Childhood Education on children's academic learning outcomes. Numerous studies on the impact of ECE on children's performance have led to two main conclusions; that ECE has long lasting effects on children's performance (Early Head Start Research and Evaluation Team, 2002; Schweinhart, 1993) and that they are strongest when the quality of early education is high (NICHD, 2002; Cost, Quality and Child Care Outcomes Study Team, 1995; Love, 2003).

However there is still debate about how long the effects last and whether they last longer, or are more powerful, for the poorest groups. This study contributes to that debate.

\section{Research Questions}

One research question was formulated to guide the conduct of this study. The research question is:

i) How ECE does influences the level of pupil preparedness in primary school?

ii) What is the influence of early childhood education on pupil and teacher interaction in primary school? 
iii) How does ECE influence curriculum content coverage of pupils who have attended the programme.

\section{Research Method}

This study adopted the ex post facto design. The population of the study consisted of teachers in the public primary school in Starehe division of Nairobi County. Krejcie and Morgan (1970) table of sample was used to select the schools and the teachers' the sample sizes. The table recommends that out of 32 schools a sample of 30 should be used. Out of a population of 932 teachers, a sample of 274 should be selected. The researcher purposively sampled 7 lower primary school teachers, from each sampled school to make a total of 210 teachers. To select the teachers from the schools the researcher used simple random sampling method. The instrument used for data collection was a questionnaire. The data collected were analyzed using descriptive statistics involving frequencies and percentages.

\section{Results and Discussion}

To establish how ECE influence pupils' preparedness, the respondents were asked to indicate whether all pupils in their classes had gone through the ECE classes. Majority of teachers 108 $(60 \%)$ indicated that pupils had attended ECE classes while $40 \%$ said their pupils had not attended.

The teachers reported that attending ECE classes enabled pupils to learn some basic counting, mathematics and speaking which was not the case among pupils that had not atended the ECE classes as reported by $70.6 \%$. The ECE had also assisted pupil to have bowel control and so could stay in the class for a given time but those who had not attended the ECE always asked permission to go to the toilet every now and then as indicated by $69.4 \%$.

A when the teachers were asked why parents did not take their pupils to the ECE centres, teachers responded as indicated in table 1 .

Table 1. Reason for taking children to the ECE centres

\begin{tabular}{|l|c|}
\hline Reasons & F \\
\hline Some feel it is not important & $70(38.9 \%)$ \\
\hline Some lack money & $91(50.6 \%)$ \\
\hline Lack of money and ignorance & $19(10.6 \%)$ \\
\hline Total & $180(100 \%)$ \\
\hline
\end{tabular}

Findings indicated that some parents did not take their children to the ECE since some felt it was not important as indicated by $38.9 \%$ of the teachers. There were $50.6 \%$ teachers who said that parents do not have money hence could not afford taking their children to the centers.

Teachers were further asked to indicate their level of agreement to statements that sought to establish the effect of attending ECE classes on pupils' preparedness. Their findings are 
presented in table 2.

Table 2. Assessment of pupils' preparedness

\begin{tabular}{|l|c|c|c|}
\hline Statement & SA & A & SD \\
\hline Attending ECD increase Pupils attentiveness & f & f & f \\
\hline ECE prepares pupils better & $80(44.4 \%)$ & $100(55.6 \%)$ & \\
\hline $\begin{array}{l}\text { ECE has great influence on pupils perform } \\
\text { later in school }\end{array}$ & $137(76.1 \%)$ & $43(23.9 \%)$ & \\
\hline $\begin{array}{l}\text { ECE is not important in later pupils } \\
\text { performance }\end{array}$ & $19(10.6 \%)$ & $62(34.4 \%)$ & $99(55 \%)$ \\
\hline Bright pupils from home need not attend ECE & & $84(46.8 \%)$ & $96(53.2 \%)$ \\
\hline
\end{tabular}

In a statement that sought to establish whether attending ECE classes increased-attentiveness for primary school, findings indicated that $76.1 \%$ strongly agreed to the statement while 23.9\% agreed. This implies that attending ECE increased preparedness in pupils to join primary school. Majority of the teachers $55.6 \%$ agreed that ECE prepared pupils better to join primary school while $44.4 \%$ of them strongly agreed to the statement. Majority of the teachers $53.2 \%$ strongly disagreed to the statement that bright pupils from home need not attend the ECE. Most of the teachers as indicated by 55\% strongly disagreed to the statement that ECE is not important in later pupil performance. The finding implies that teachers were of the opinion that ECD was important in preparing pupils for primary school.

The teachers were also asked to state how ECE affect learning outcomes in the lower primary:

\begin{tabular}{|l|c|}
\hline Influence of ECE on curriculum coverage & F \\
\hline ECE created good learning atmosphere at primary school & $43(23.9 \%)$ \\
\hline Use of appropriate teaching aids prepared pupils for primary school & $53(39.4 \%)$ \\
\hline $\begin{array}{l}\text { Using various teaching approaches prepares pupils for primary } \\
\text { schools }\end{array}$ & $38(21.1 \%)$ \\
\hline Good preparation in ECE facilitated at primary school & $46(25.6 \%)$ \\
\hline Total & $180(100 \%$ \\
\hline
\end{tabular}

The teachers were asked to indicate what influenced performance in the lower primary school. When teachers were asked to indicate how ECE influence curriculum content in the lower primary school, findings revealed that the learning at the school was easier since pupils had been prepared at the ECE classes as indicated by $23.9 \%$, while $29.4 \%$ said the ECE influenced curriculum content by use of appropriate teaching aids at the ECE classes. There were $21.1 \%$ who indicated that use of appropriate teaching approaches facilitated curriculum content coverage at the primary school. Further findings showed that good preparation at the ECE had an influence on curriculum content coverage at the primary schools. 
To establish the general performance of pupils in their classes, the teachers were asked to indicate the general performance of pupils in their class as shown table 3.

Table 3. General performance of pupils

\begin{tabular}{|l|c|}
\hline \multicolumn{1}{|c|}{ Reasons } & $\mathrm{F}$ \\
\hline $\begin{array}{l}\text { Pupils who have attended ECD are able basic to master basic concepts } \\
\text { faster }\end{array}$ & $50(27.7 \%)$ \\
\hline Pupils who attended ECD are able to follow instruction easily & $68(37.1 \%)$ \\
\hline $\begin{array}{l}\text { Pupils who have attended ECD are fluent in reading and can recognize } \\
\text { numbers }\end{array}$ & $46(25.6 \%)$ \\
\hline $\begin{array}{l}\text { Pupils who have attended ECD are already exposed to reading and } \\
\text { writing skills }\end{array}$ & $16(10.6 \%)$ \\
\hline \multicolumn{1}{|c|}{ Total } & 180 \\
\hline
\end{tabular}

Data revealed that pupils who had attended the ECE were able to master basic concepts faster than those who had not attended as indicated by $27.8 \%$ while $37.1 \%$ reported that pupils who have attended ECE are able to follow instructions easily, $25.6 \%$ indicated that pupils who have attended ECE were fluent in reading and can recognize numbers, while (10.6\%) said that pupils who have attended ECD are already exposed to reading and writing skills. The findings imply that pupil's attendance to the ECE programmes had an impact on pupil's cognitive levels.

The teachers were also asked whether those pupils who had not gone through the ECE classes performed better. Findings revealed that 24(13.3\%) of the teachers said those pupils who had not attended ECE classes had poorer performance. The teachers said were that some pupils were naturally gifted and were able to adapt well in standard one. They also responded that some pupils had received coaching at home hence they were able to adapt well in class.

The teachers were asked to indicate how they agreed or disagreed with the statement that there is no difference in performance between pupils who have attended ECE and those who have not. The response was $62(34.4 \%)$ disagreed while $118(65.6 \%)$ strongly disagree. Majority of teachers 84(46.7\%) strongly agreed 96(53.3\%) agreed that attending ECE assisted pupils later in adapting better in primary school. Asked whether performance in lower primary school depended on attendance on ECE, findings revealed that 53(29.4\%) strongly agreed, 19(10.6\%) disagreed, 62(34.4\%) agreed while the rest were undecided.

The teachers were asked whether they recommended children to attend ECE before joining primary school. They agreed that children should be taken to ECE before joining primary school. They were asked whether they had pupils from the public and private. They all agreed that they had pupils from both private and public ECE centers. Asked which group performed better, finding revealed that pupils from the private ECE centers performed better as indicated by $115(63.9 \%)$. Those who said that pupils from public centers performed better were 46 $(25.6 \%)$. Nineteen $(10.6 \%)$ said both pupils from private and public performed equally. 


\section{$\Lambda$ Macrothink}

\section{Conclusion}

The study concluded that ECE prepares pupils to join primary school by enabling them to learn some basic counting, mathematics and speaking which was not the case among pupils that had not attended the ECE. It was also concluded that pupils who had attended ECE were able to interact with fellow pupils and teachers better that those who had not attended ECE. It was also concluded that pupils who had attended the ECE had usually lower scores at least at the beginning in form one. It was also concluded that pupils from private ECEs performs better than those who had attended public centers.

\section{Recommendation}

The study recommended that parents should be sensitized on the need to take their children to the ECE before taking them to formal primary schools. It was also recommended that public ECE centers should be well organized to offer better education to the pupils. Finally, it was recommended that teachers should take special care of the pupils who had not attended ECE so that they are able to fit better in class.

\section{References}

Bainbridge, J., Marcia, M., Sakiko, T., \& Waldfoge, J. 1. (2004). Who Gets an Early Education? Family Income and the Gaps in Enrollment of 3 to 5 year olds from 1968-2000.

Barnett, S. (1993). Benefits of Compensatory Preschool Education. Journal of Human Resources, 279-312.

Barnett, S. (1995). Long-Term Effects of Early Childhood Programs on Cognitive and School Outcomes. The Future of Children, 25-50. http://dx.doi.org/10.2307/1602366

Berlinski, S., \& Galiani, S. (2004). The Effect of a Large Expansion of Pre-Primary School Facilities on Preschool Attendance and Maternal Employment. Institute for Fiscal Studies Working Paper \# 0430, London.

Blau, D., \& Currie, J. (2004). Preschool, Day Care, and After School Care: Who's Minding the Kids? NBER Working Paper \# 10670, Cambridge MA.

Borg, W. R., \& Gall, M. D. (1989). Educational Research: An Introduction (5lh ed.). New York: Longman.

Cascio, E. (2004). Schooling Attainment and the Introduction of Kindergartens into Public Schools.

Duflo, E. (2001). Schooling and Labor Market Consequences of School Construction in Indonesia: Evidence from an Unusual Policy Experiment. American Economic Review, 91, 795-813. http://dx.doi.org/10.1257/aer.91.4.795

Duncan, G., \& Christina, G. (2000). Selection and Attrition in the NICHD Child Care Study's Analyses of the Impacts of Child Care Quality on Child Outcomes. Mimeo, Northwestern.

Gregory, 1. (2004). The effects of preschool education on children's academic development 
and socialization in primary grades. A dissertation completed at The Center for Education, Widener University, One University Place, Chester, PA 19013.

Krejcie, R., \& Morgan, D. (1970). Determining Sample Size for Research Activities. Journal of Educational and Psychological Measurement, 30(3).

Magnuson, A., Ruhm, C., \& Waldfogel, J. (2005). Does Prekindergarten Improve School Preparation and Performance? Economics of Education Review, forthcoming.

Ministry of Education. (2008). Syllabus for Early Childhood Education. Nairobi: Government Printers.

Myers. (1995). Thinking Early Childhood Education. Newyork: Longhorn.

Orodho, J. A. (2002). Techniques of Writing Research Proposals and Reports in Education and Social Sciences. Nairobi: Masola Publishers.

Ramey, S, L., \& Craig, T. (2000). The Effects of Early Childhood.

Sammons, P., Sylva, K., Melhuish, E. C., Siraj-Blatchford, I., Taggart, B., Elliot, K., \& Marsh, A. (2004). The Effective Provision of Pre-School Education (EPPE) Project: Technical Paper 9 - Report on age 6 assessments. London: DfES/Institute of Education, University of London.

Schweinhart, L. J., Barnes, H., \& Weikart, D. (1993). Significant benefits the High/Scope Perry Pre-school Study through age 27. Ypsilanti, Michigan: High/Scope Press.

Sylva, K., \& Pugh, G. (2005). Transforming the early years in England. Oxford Review of Eructation, 31(1), 11-27. http://dx.doi.org/10.1080/0305498042000337165

Tiwari, S. (1997). Nutritional status and physical development of children of an Urbanslum community of Varanasi MA Dissertation (Home Sc.) (pp. 1-38). Banaras Hindu University, Varanasi.

United Nations Children Fund. (1998). The state of the world's children (pp. 1-41).

Vandell, D. L., \& Barbara, W. (2000). Child Care Quality: Does It Matter and Does It Need to be Improved? Institute for Research on Poverty Special Report, University of Wisconsin at Madison, November, 20.

\section{Copyright Disclaimer}

Copyright for this article is retained by the author(s), with first publication rights granted to the journal.

This is an open-access article distributed under the terms and conditions of the Creative Commons Attribution license (http://creativecommons.org/licenses/by/3.0/). 